Kerri Robertson MD,

M. Joanne Douglas MD, FRCPC, Graham H. McMorland MD, FRCPC

\title{
Epidural fentanyl, with and without epinephrine for post- Caesarean section analgesia
}

Using a double-bolus technique, the efficacy and safety of epidural fentanyl with and without epinephrine 1:400,000 for post-Caesarean section analgesia was examined in 30 patients. The addition of $25 \mu \mathrm{g}$ epinephrine to the fentanyl $(100 \mu \mathrm{g})$ did not potentiate the speed of onset but did significantly prolong the duration of action of the second dose. The only side effect encountered was prurirus, which was significantly increased (from 17-44 per cent) when epinephrine was added. The results indicate a clinical advantage of prolonging the duration of action of fentanyl for past-Caesarean Section analgesia with the addition of epinephrine, but the cumbersame and time-consuming nature of a double-bolus technique limits its clinical value. The relative safety of epidural fentanyl with and without epinephrine was confirmed by the absence of respiratory depression, drowsiness or hypotension in all patients.

Key words

PAIN: postoperative; ANALGESICS: narcotic; ANAESTHETIC TECHNIQUES: epidural.

From the Department of Anaesthesia, University of British Columbia and Grace Hospital, Vancouver, British Columbia.

Address correspondence to: Dr. G.H. McMorland, Department of Anaesthesia, Grace Hospital, 4490 Oak Street, Vancouver, British Columbia, V6H 3V5.
As early as 1979 , administration of single bolus doses of epidural fentanyl was described for routine use after elective Caesarean section. Onset of analgesia occurs in four to ten minutes, with the peak effect in 20 minutes. Maximum duration of analgesia, however, is only 200 to 240 minutes. The high lipid solubility of fentanyl promotes its rapid uptake from the epidural space. This may limit its access to the nociceptive receptors in the dorsal horn of the spinal column, resulting in a shortened duration of action. The more water soluble narcotics act largely due to depot formation in the cerebrospinal fluid (CSF) and subsequent cephalad diffusion. The pregnant woman, with her increased epidural blood flow, is an ideal patient in whom to study the effects of epinephrine as an adjuvant to a bolus injection of epidural fentanyl, as it has been suggested that epinephrine reduces the vascular absorption of bolus epidural narcotics.

In our institution, preservative-free morphine is the only narcotic currently administered for postCaesarean section analgesia via the epidural route. Despite its known clinical efficacy there are a number of concerns regarding its use. These include a variable duration of action between patients, delayed onset, an 80 per cent incidence of pruritus, and the possibility of late respiratory depression, especially when additional parenteral narcotic analgesia is given. In an attempt to address these concerns, a double-blind randomized trial comparing the efficacy and safety of a double bolus administration of epidural fentanyl $100 \mu \mathrm{g}$, with and without 1:400,000 epinephrine, was conducted. The objective was to demonstrate whether the use of an epinephrine containing solution of fentanyl administered in two consecutive doses would provide analgesia of sufficient total duration 
to be adequate for clinical use, coupled with an accelerated speed of onset and minimum adverse effects.

\section{Methods}

Following approval from the Screening Committee for Research Involving Human Subjects, informed consent was obtained from each patient. Thirty ASA physical status I patients scheduled for elective Caesarean section (with epidural anaesthesia) were randomly assigned to one of two groups to receive postoperatively:

1. Fentanyl $100 \mu \mathrm{g}$ diluted with 0.9 per cent saline to a concentration of $10 \mu \mathrm{g} \cdot \mathrm{ml}^{-1}$ or

2. Fentanyl $100 \mu \mathrm{g}$ diluted with 0.9 per cent saline to a concentration of $10 \mu \mathrm{g} \cdot \mathrm{ml}^{-1}$ plus 1:400,000 epinephrine.

A conventional epidural technique using carbonated lidocaine with 1:400,000 epinephrine was employed. All patients received $30 \mathrm{ml}$ of $0.3 \mathrm{M}$ sodium citrate P.O. 90 minutes preoperatively. Following a one litre intravenous bolus of Ringer's Lactate, with the patient sitting, or in the left lateral position, the epidural space was identified at L2-3 or L $3-4$, by a loss of resistance technique. A catheter was advanced $3 \mathrm{~cm}$ cephalad through a \#17 Tuohy needle. With the patient supine and a wedge under the right hip, carbonated lidocaine with 1:400,000 epinephrine was used for a $3 \mathrm{ml}$ test dose and subsequent incremental doses to a total volume adequate to establish a sensory level to T4. Monitoring included blood pressure and ECG. An intravenous bolus and infusion of oxytocin was given following the clamping of the cord. Intraoperatively, the patient received no additional parenteral medication, except ephedrine if hypotension occurred.

On completion of the surgery, the epidural catheter was left in situ and the patient was taken to the Recovery Room. With the onset of discomfort and the patient supine, the epidural catheter was injected with one of the above solutions. The preparation and injection of the test solution was performed by the staff anaesthetist and all subsequent observations were made by the ward nurses and house staff, who were blinded to the solution used. The catheter was flushed with $3 \mathrm{ml}$ of normal saline and routine vital signs including blood pressure, heart rate and respiratory rate were noted every 30 minutes for two hours and then hourly. A second bolus of fentanyl, identical in composition and volume to that injected in the recovery room, was administered upon patient request for analgesia and then the epidural catheter was removed.

Latency of onset and duration of analgesia for the first and second doses were recorded. A visual analogue pain scale was employed in an attempt to quantify pain relief. The patient was asked to place an " $x$ " on a $10 \mathrm{~cm}$ vertical line to indicate the intensity of the pain. The scale ranged between the two extremes of no pain, to as much pain as one could possibly imagine. This was completed at four specific time intervals:

1. Postoperatively on arrival in the recovery room, to assess the discomfort of the epidural catheter insertion; to establish a baseline of the patient's pain threshold for further comparison;

2. 15 minutes following the epidural injection of fentanyl;

3. 90 minutes following the epidural injection of fentanyl;

4. At the onset of discomfort, as indicated by the patient.

All patients were observed by the nursing staff on the ward for 24 hours postpartum. Nausea, vomiting, vertigo, urinary retention, motor weakness, respiratory depression, drowsiness, hypotension and pruritus were carefully documented by an independent observer. Hourly measurements of heart rate, respiratory rate and blood pressure were recorded. When the patient again complained of pain (after the second fentanyl dose), parenteral narcotic analgesia was administered as required. The nursing staff were instructed to notify the anaesthetist if there was any evidence of respiratory depression (respiratory rate $<10$ per minute), hypotension, or if the patient seemed unduly drowsy or unresponsive.

The data were analyzed in the following manner. The time of onset and duration of analgesia for the two groups were compared using an independent 2 -tailed " $t$ " test of the mean value. The observed incidence of side effects was analyzed using the Chi squared distribution. The results of these tests were considered significant if the chance of random occurrence was less than five per cent. All values are expressed as the mean \pm standard error.

\section{Results}

Thirty patients were studied. Sixteen patients re- 
TABLE I Population studied

\begin{tabular}{lrc}
\hline & $\begin{array}{l}\text { Fentanyl } \\
(n=16)\end{array}$ & $\begin{array}{l}\text { Fentanyl with } \\
\text { epinephrine } \\
(n=14)\end{array}$ \\
\hline $\begin{array}{l}\text { Age distribution } \\
\text { (years) }\end{array}$ & $30 \pm 1.76$ & $29.33 \pm 0.98$ \\
$\begin{array}{l}\text { Pain of epidural insertion } \\
\begin{array}{l}\text { Intensity of discomfort } \\
\text { necessitating second epidural } \\
\text { fentanyl bolus }\end{array}\end{array}$ & $1.78 \pm 0.71$ & $1.49 \pm 0.36$ \\
\hline
\end{tabular}

Mean \pm SEM

ceived fentanyl $100 \mu \mathrm{g}$ and 14 received fentanyl $100 \mu \mathrm{g}$ with $25 \mu \mathrm{g}$ of epinephrine added. Two patients given plain fentanyl and three given fentanyl with epinephrine had the epidural catheter removed prior to the second fentanyl dose. The patient population of the two trial groups was similar in age distribution, pain sensitivity and assessment of the intensity of discomfort necessitating a second epidural fentanyl bolus (Table I).

The mean duration of action of plain epidural fentanyl was 180 minutes with a time of onset of 8.5 minutes. The addition of epinephrine did not significantly prolong the duration of action nor increase the speed of onset (Table II).

Table III indicates the time of onset and duration of analgesia for the patients who received a second epidural fentanyl dose. No significant difference was noted for the time of onset of initial analgesic effect for fentanyl with or without epinephrine. Using epinephrine as an adjuvant, the duration of action was significantly prolonged for the second top-up dose at 237 minutes as compared to plain fentanyl at 166 minutes.

The only side effect encountered was pruritus. There was a 17 per cent incidence of pruritus in patients receiving plain fentanyl, but this was significantly increased to 44 per cent with the epineph-

TABLE I Analgesia - first dose

\begin{tabular}{lcc}
\hline & $\begin{array}{l}\text { Fentanyl } \\
(n=16)\end{array}$ & $\begin{array}{l}\text { Fentanyl with } \\
\text { epinephrine } \\
(n=14)\end{array}$ \\
\hline Time of onset & $8.50 \pm 0.6$ & $6.93 \pm 0.88$ \\
Duration of analgesia & $180 \pm 19$ & $200 \pm 18$ \\
\hline
\end{tabular}

Mean \pm SEM (minutes).
TABLE III Analgesia - second dose

\begin{tabular}{lcc}
\hline & $\begin{array}{c}\text { Fentanyl } \\
(n=14)\end{array}$ & $\begin{array}{l}\text { Fentanyl with } \\
\text { epinephrine } \\
(n=11)\end{array}$ \\
\hline Time of onset & $\begin{array}{c}9.71 \pm 0.94 \\
166 \pm 15\end{array}$ & $\begin{array}{c}6.91 \pm 1.28 \\
237 \pm 27^{*}\end{array}$ \\
\hline
\end{tabular}

Mean \pm SEM (minutes).

$* p<0.05$.

rine-containing preparation. Of note, the distribution of the pruritus was segmental, involving primarily the trunk and chest, with no facial spread. This is in contrast to epidural morphine where the most troublesome itching is facial in distribution. There was no consistency in the incidence of itching between subsequent fentanyl doses in the same patient. All cases were mild and self-limited. Two patients received diphenhydramine $50 \mathrm{mg}$ without effect. No cases of respiratory depression, drowsiness, hypotension, muscular weakness, nausea, vomiting, vertigo or urinary retention were seen.

\section{Discussion}

This study was designed to satisfy the requirements of simplicity, minimal interference with established obstetrical anaesthetic practice and above all, patient safety and acceptance. A literature search revealed only one previous study describing the use of fentanyl with epinephrine in the epidural space. Fentanyl $100 \mu \mathrm{g}\left(10 \mu \mathrm{g} \cdot \mathrm{ml}^{-1}\right)$ was chosen as an optimum dose for analgetic effect. As each patient received an epinephrine-containing solution of carbonated lidocaine prior to entering the study and with the pharmacokinetics of epinephrine in the epidural space not fully understood, a minimum concentration of 1:400,000 epinephrine (2.5 $\mu \mathrm{g} \cdot \mathrm{ml}^{-1}$ ) was used. End tidal $\mathrm{CO}_{2}$ measurement in the postpartum period was felt to be invasive, so respiratory rate was chosen to assess respiratory performance.

Concerns about respiratory depression on the ward were proven unfounded. The relative safety of epidural fentanyl with and without epinephrine 1:400,000 was confirmed by the absence of respiratory depression, drowsiness, or hypotension in all patients.

The only side effect encountered was pruritus. Welchew ${ }^{7}$ reported an incidence of pruritus of 45 per cent, following the use of fentanyl $50 \mu \mathrm{g}$ with 
$50 \mu \mathrm{g}$ of epinephrine. This is consistent with the findings in this study using fentanyl $100 \mu \mathrm{g}$ with $25 \mu \mathrm{g}$ of epinephrine. No significant difference was seen in Welchew's study with fentanyl $100 \mu \mathrm{g}$ with or without epinephrine 1:200,000. In our study, it is interesting that the itching seemed to be limited to the chest and abdomen, suggesting that epidural fentanyl did not diffuse cephalad to a clinically significant degree.

The fact that there was no demonstrable difference in onset time or duration of action between the first dose of fentanyl, with or without epinephrine, may be a reflection of the small patient population and an inherent flaw within the study design. Persistence of the epinephrine (contained in the carbonated lidocaine) within the epidural space might be expected to influence the duration of action of the first dose of plain epidural fentanyl. If this effect was significant one might expect to demonstrate a difference between the duration of action of the first and second doses of plain fentanyl. This was not found

In conclusion, this study has shown that the addition of epinephrine to epidural fentanyl for post-Caesarean section analgesia significantly prolongs its duration of action following a second dose, with an associated increase in the incidence of pruritus. Epidural fentanyl with epinephrine provides adequate postoperative analgesia, without serious potentiation of side effects. The use of a double bolus technique is both time-consuming and cumbersome which limits its value for clinical use. The search continues for a synthetic opiate agonist of high lipid solubility with optimum analgetic potency and minimum adverse effects, for epidural use.

\section{References}

1 Wolfe $M J$, Nicholas $A D G$. Selective epidural analgesia. Lancet $1979 ; 2: 150$.

2 Wolfe MJ, Davies GK. Analgesic action of extradural fentanyl. Br J Anaesth 1980; 52: 357.

3 Mather LE. Clinical pharmacokinetics of fentanyl and its newer derivatives. Clinical Pharmacokinetics 1983; 8: 371 .

4 Bromage PR, Camparesi EM, Durant PA, Nielsen $C H$. Influence of epinephrine as an adjuvant to epidural morphine. Anesthesiology 1983; 58: 257.

5 Collier $E$. Epinephrine and epidural narcotics. Anesthesiology 1984; 60 : 168.
6 Ohmhaus $E E$, Adler $R$. Methodological problems in measurement of pain: a comparison between the verbal rating scale and the visual analogue scale Pain I, 1975; 379.

7 Welchew EA. The optimum concentration for epidural fentanyl (a randomized, double-blind comparison with and without 1:200,000 adrenalin). Anaesthesia 1983; 38: 1037.

Résumé

L'efficacité et la sécurité du fentanyl en injection épidurale associé ou non d̀ l'épinephrine 1:400,000 pour l'analgésie post-césarienne ont été étudiées chez 30 patientes utilisant la technique du double-bolus. L'addition de $25 \mu \mathrm{g}$ d'épinephrine à $100 \mu \mathrm{g}$ de fentanyl en injection épidurale n'a pas potentialisé la vitesse du début d'action mais a prolongé significativement la durée d'action de la seconde dose. Le seul effet secondaire encouru était le prurit qui avait significativement augmenté de 17 à 44 pour cent quand l'épinephrine a êté ajoutée. Les résultats indiquent l'avantage clinique de l'addition de l'épinephrine afin de prolonger la durée $d$ 'action du fentanyl administré en épidurale pour l'analgésie post-césarienne. Cependant, la technique du double-bolus était encombrante et prenant du temps, limitera sa valeur clinique. La sécurité relative du fentanyl en injection épidurale avec ou sans épinephrine a été confirmée par l'absence de dépression respiratoire somnolence ou hypotension chez toutes les patientes. 